\title{
AMASYA ROMA DÖNEMİ İNSANLAR
}

\section{Hanife AKBACAK \\ Pinar GÖZLÜK KIRMIZIOĞLU**}

Atıf/O: Akbacak, Hanife, Gözlük Kırmızıŏlu, Pınar (2018). Amasya Roma Dönemi İnsanlan, Hitit Üniversitesi Sosyal Bilimler Enstitüsü Dergisi, ANARSAN Sempozyumu Özel Sayısı, Ekim 2018, Cilt 11 Sayı 2, ss. 1631-1650

Özet: Bu çalışmada, 1992-2012 yıllar arasında Amasya ili ve çevresinde, Roma Dönemi'ne tarihlendirilen çeşitli arkeolojik alanlarda yapılan kazılar sonucu ele geçirilen insan iskeletleri, paleodemografik ve morfolojik yapinin saptanmas,, ağı sağlığının belirlenmesi amactyla incelenmiştir. İncelenen 56 bireyin 2'si bebek (\% 3,57), 11'i çocuk (\% 19,64), 15'i kadin (\% 26,79), 13'ü erkek (\% 23,21) ve 15 'i de cinsiyeti saptanamayan bireylerden $(\%$ 26,79) oluşmaktadır. Erişkin bireylerin yaş ortalaması 39,4 yıldır. Toplum genelinde boy uzunluğu, Pearson'a göre (1899) 161,58 (n: 4), Trotter-Gleser'e göre (1952) 167,85 (n: 4) ve Sağır'a (2000) göre 162,07'dir (n: 4). Erişkinlerde daimi dişlerde ve çenelerde, diş aşınması (\% 56,98), diş çürügü (\% 4,65), hypoplasia (\% 4,65), diştaşı (\% 2,91), apse (\% 1,35), alveol kaybı (\% 36,3), ölüm öncesi (antemortem) diş kaybı $(\%$ 6,28) gibi lezyonlar saptanmıştır.

Anahtar Kelimeler: Amasya, Roma Dönemi, Paleodemografi, Boy uzunluğu, Ağız sağlı̆̆ı.

\section{The People Of Amasya Roman Period}

Citation/O: Akbacak, Hanife, Gözlük Kirmızıoğlu, Pinar (2018). The People of Amasya Roman Period. Hitit University Journal of Social Sciences Institute, Symposium of AAHA, Special Issue, Year 11 Volume 2 October 2018, ss. 1631-1650

Abstract: The aim of this study is to determine paleodemographic and morphological structure and oral health of the human skeletons that were excavated in various archaeological sites dated to the Roman period in the province of Amasya between 1992 and 2012. Of the 56 individuals, 2 were infants (\%3.57), 11 were children (\%19.64), 15 were women (\% 26.79), 13 were men (\% 23.21) 15 were

Makale Geliş Tarihi:16.09.2018 / Makale Kabul Tarihi: 01.10.2018

Bu makale Turnitin programinda kontrol edildi. This article was checked by Turnitin.

Bu makale ANARSAN sempozyumunda sunulmuş aynı başlıklı bildirinin tam metnidir.

Yüksek Lisans Mezunu, Cumhuriyet Üniversitesi, Antropoloji Bölümü, hanife.akbacak@gmail.com

${ }^{* *}$ Prof. Dr., Cumhuriyet Üniversitesi, Antropoloji Bölümü, pinar.gozluk@gmail.com 
adults $(\% 26,79)$ whose gender can not be determined. The average age of adult individuals is 39.4 years. According to Pearson (1899), Trotter-Gleser (1952) and Sağır (2000), stature was 161,58 (n: 4), 167,85 (n: 4) ve Sağır (2000) 162,07 (n: 4) respectively in society. In adults permanent teeth and jaws, dental attrition (56,98\%), dental caries (4,65\%), hypoplasia (4,65\%), dental calculus (2,91\%), abscess (1,35\%), alveolar bone loss (36,3\%) and antemortem tooth loss 6,28\% were determined.

Keywords: Amasya, Roman Period, Paleodemography, Stature, Oral health.

\section{I) GİRIŞ}

Amasya ili, Karadeniz bölgesinin orta kesiminin iç kısmında, Canik Dağları'nın güneyinde yer almaktadır. Şehir, deniz seviyesinden $400 \mathrm{~m}^{2}$ yükseklikte, Yeşilırmak nehri ile Merzifon ovasını sulayan Terkesan Irmağı'nın birleştiği yerin batısında, Yeşilırmak'ın açtığı iki tarafı yüksek kayalıklarla çevrili dar bir vadide kurulmuştur (Şahin ve Emecen, 1991; Çatal, 2009).

Amasya ili ve çevresi eski dönemlerden günümüze kadar birçok uygarlığa ev sahipliği yapmıştır. Amasya'daki ilk yerleşmeler Kalkolotik Çağ’a (MÖ 55003000) kadar uzanmaktadır (Er, 2009). Tarım için verimli toprakları, ticaret yolları üzerinde bulunması bu bölgenin tercih edilmesinde önemli etkenlerdendir. Genel olarak dağlık bir yapıya sahip olsa da, çok önemli ve büyük, aynı zamanda da tarıma elverişli topraklara sahip ovaları bünyesinde barındırmaktadır (Özbey, 2010). Amasya, yaklaşık 500 yıl kadar Romalıların egemenliği altında varlığını sürdürmüştür. Roma idaresi döneminde Amasya'da pek çok kiliseler, saraylar ve mezarlar yapılmış olmakla birlikte bunların birçoğu tahrip olmuştur (Kertil, 2014).

1992-2012 yılları arasında Amasya ili ve çevresinde yer alan ve Roma Dönemi'ne tarihlendirilen arkeolojik alanlarda, Amasya Müze Müdürlüğü başkanlığında kurtarma kazıları gerçekleştirlmiştir. Bu kazılar sonucunda bulunan iskeletler, genelde Amasya şehir merkezinde 2. ve 3. yüzyıllarda yaygın olarak kullanılan yarım tonozlu taş kapaklı Roma mezarlarından çıkarılmıştır (Çalıştığımız dönemde Amasya Müze Müdürü olarak görev yapan Celal Özdemir ile sözlü görüşme).

Bu çalışma, Amasya ili ve çevresinde Roma Dönemi'nde yaşamış insanların paleodemografik ve morfolojik yapılarının saptanması, ağız sağlıklarının anlaşılabilmesi amacıyla gerçekleştirilmiştir. 


\section{II) MATERYAL VE METOT}

Çalışmamızın materyalini, 1992-2012 yılları arasında Amasya ili ve çevresinde Roma Dönemi ile tarihlendirilen arkeolojik alanlarda, Amasya Müze Müdürlüğü başkanlığında yapılan kurtarma kazıları sonucunda ele geçirilen toplam 56 bireye ait iskelet kalıntıları oluşturmaktadır. Bulunan iskeletler, Cumhuriyet Üniversitesi, Edebiyat Fakültesi, Antropoloji Bölümü, Paleoantropoloji laboratuvarında getirilerek gerekli temizlik ve onarım işlemleri gerçekleştirilmiştir. İskelet kalıntılarının karışık ve parçalı olması nedeniyle öncelikle birey ayırımına gidilmiş, hangi kemiğin hangi bireye ait olduğunun saptaması zor olduğu için, kemikler ayrı ayrı sınıflandırılmış ve numaralandırılmıştır. Ardından bireylerde cinsiyet tayini ve yaş tahmini yapılmıştır. Bireylerde cinsiyet belirlenirken kemiklerin genel morfolojik yapılarına bakılmış, yaşlandırmada ise, bebek ve çocuklarda uzun kemik uzunlukları, genç erişkinlerde epifizlerin kaynaşma yaşları, erişkin bireylerde ise symphysial yaşlandırma, dental aşınma, claviculanın kesiti, femur ve humerusun proksimal kesitindeki spongiosa dokusunun yapis1 dikkate alınmıştır (WEA, 1980: Ubelaker, 1978: Brothwell, 1981: Olivier, 1969: White, 2000: Hillson, 1990: Kaur ve Jit, 1990: Szilvassy ve Kritscher, 1990). Bireylerde boy uzunluğunun belirlenebilmesi için uzun kemiklerin maksimum uzunlukları ölçülmüş (Buikstra ve Ubelaker, 1994; Olivier, 1969), ortalama boy uzunlukları Pearson (1899), Trotter-Gleser (1952) ve Sağır'ın (2000) boy regrasyon formülleri kullanılarak hesaplanmıştır. Paleodemografik çalışmalarda Ubelaker'ın (1978), paleopatolojik bulguların saptanmasinda da, Ortner ve Putschar'ın (1985), Brothwell'in (1981), Hillson'ın (1990) ve Buikstra ve Ubelaker'in (1994) çalışmalarından yararlanılmış, diş aşınma derecelerinde Bouville ve diğ. (1983) geliştirmiş olduğu diş aşınma ölçeği dikkate alınmıştır.

\section{III) BULGULAR VE DEĞERLENDİRME}

\section{A) Paleodemografik dağılım}

Amasya ili ve çevresinde yapılan arkeolojik kazılar sonucunda ele geçen ve Roma Dönemi'ne tarihlendirilen bireylerin paleodemografik dağılımına bakıldığında, toplam 56 bireyin 2'si (\% 3,57) bebek, 11 'i $(\%$ 19,64) çocuk, 15 ’ (\% 26,79) kadın, 13’ü (\% 23,21) erkek ve 15’i de (\% 26,79) yeterli cinsiyet kriteri bulunamadığı için cinsiyeti belirlenemeyen bireyler olarak saptanmıştır (Akbacak, 2018) (Tablo 1). 
Tablo 1: Amasya Roma Dönemi bireylerinin paleodemografik dağılımı

\begin{tabular}{|l|c|c|}
\hline Cinsiyet & $\mathrm{n}$ & $\%$ \\
\hline Bebek & 2 & 3,57 \\
\hline Çocuk & 11 & 19,64 \\
\hline Kadın & 15 & 26,79 \\
\hline Erkek & 13 & 23,21 \\
\hline Cins. Bilinm. & 15 & 26,79 \\
\hline Toplam & 56 & 100 \\
\hline
\end{tabular}

n: Birey say1s1

İncelenen bireylerin \% 76,79'u erişkin bireylerden (n: 43), \% 23,21'i bebek ve çocuklardan (n: 13) oluşmaktadır. Bebek ve çocuklarda ikişerli yaş aralıklarına göre yaş dağılımı incelendiğinde, en fazla ölümlerin 4-5,9 (\% $30,77)$ yaş aralığ arasında gerçekleştiği görülmektedir (Tablo 2). 10-15,9 yaş aralığında bireylere rastlanmamıştır.

Tablo 2: Bebek ve çocuklarda ikişerli yaş aralıklarına göre yaş dağılım tablosu

\begin{tabular}{|l|c|c|}
\hline Yaş Grupları & $\mathrm{n}$ & $\%$ \\
\hline $0-1,9$ & 2 & 15,38 \\
\hline $2-3,9$ & 2 & 15,38 \\
\hline $4-5,9$ & 4 & 30,77 \\
\hline $6-7,9$ & 2 & 15,38 \\
\hline $8-9,9$ & 2 & 15,38 \\
\hline $10-11,9$ & - & 0 \\
\hline $12-13,9$ & - & 0 \\
\hline $14-15,9$ & - & 0 \\
\hline $16-17,9$ & 1 & 7,69 \\
\hline Toplam & 13 & 100 \\
\hline
\end{tabular}

n: Birey say1s1

Kadınlarda ve erkeklerde beşerli yaş aralığına göre yaş dağılımına bakıldığında, en fazla ölümlerin kadınlarda 40-45, erkeklerde ise 25-30 ve 30-35 yaş aralıklarında yoğunlaştığı görülmektedir (Tablo 3). 
Tablo 3: Kadın ve erkek bireylerde beşerli yaş aralıklarına göre yaş dağılım tablosu

\begin{tabular}{|l|c|c|c|c|c|c|}
\hline Yaş Grupları & Kadın & $\%$ & Erkek & $\%$ & Toplam & $\%$ \\
\hline $20-24,9$ & 1 & 6,67 & - & 0 & 1 & 3,57 \\
\hline $25-29,9$ & 2 & 13,33 & 3 & 23,1 & 5 & 17,86 \\
\hline $30-34,9$ & - & 0 & 3 & 23,1 & 3 & 10,71 \\
\hline $35-39,9$ & 3 & 20 & 2 & 15,4 & 5 & 17,86 \\
\hline $40-44,9$ & 5 & 33,33 & 2 & 15,4 & 7 & 25 \\
\hline $45-49,9$ & 3 & 20 & 1 & 7,69 & 4 & 14,29 \\
\hline $50-54,9$ & 1 & 6,67 & 2 & 15,4 & 3 & 10,71 \\
\hline Toplam & 15 & 100 & 13 & 100 & 28 & 100 \\
\hline
\end{tabular}

Bu çalışmada, bireyler 0-2,5 yaş aralığı bebek, 2,5-17,9 yaş aralığı çocuk, 18-24,9 yaş aralığ1 genç erişkin, 25-44,9 yaş aralığ1 orta erişkin, 45 yaş ve üstü ileri erişkin olarak değerlendirilmiştir. Buna göre, erişkin bireylerin \% 3,57'si genç erişkinlerden, \% 71,42'si orta erişkinlerden ve \% 25’i ileri erişkinlerden oluşmaktadır. Görüldügü üzere, incelenen bireyler toplum genelinde orta erişkin yaş grubunda yoğunlaşmaktadır.

Amasya bireylerinde kadınlarda ortalama yaşam uzunluğu 40,3 yıl, erkeklerde 38,8 yıl olarak bulunmuştur. Kadın ve erkek bireyler birlikte değerlendirildiğinde, ortalama yaşam uzunluğu 39,55 yıldır. Bu sonuç bize, kadınların erkeklere göre daha uzun ömürlü olduklarını göstermektedir.

\section{B) Boy uzunluğu}

Bireylerde morfolojik yapının en güzel göstergesi boy uzunluğudur. Amasya Roma Dönemi bireylerinde morfolojik yapının saptanabilmesi amacıyla, sağlam olarak bulunan 3 kadın ve 1 erkek bireye ait sol femurlardan maksimum uzunluk ölçüleri alınmış, Pearson (1899), Trotter - Gleser (1952) ve Sağır'ın (2000) boy regresyon formüllerine göre ortalama boy uzunlukları hesaplanmıştır. Kadın ve erkek bireyler birarada değerlendirildiğinde bu bireylerin ortalama boy uzunlukları, Pearson'a (1899) göre 161,58 (n: 4), Trotter-Gleser'e (1952) göre 167,85 (n: 4) ve Sağır'a (2000) göre 162,07 (n: 4) olarak saptanmıştır. Kadınlarda ve erkeklerde her üç formüle göre de hesaplanan boy uzunluğu Tablo 4'te verimiştir. Görüldüğü üzere, erkekler kadınlardan daha uzun boyludur. 
Tablo 4: Amasya bireylerinde boy uzunluğu

\begin{tabular}{|l|c|c|c|c|c|c|}
\hline & $\mathrm{n}$ & Kadın & $\mathrm{n}$ & Erkek & $\mathrm{n}$ & Genel \\
\hline Pearson (1899) & 3 & 155,76 & 1 & 167,41 & 4 & 161,58 \\
\hline Trotter-Gleser (1952) & 3 & 164,78 & 1 & 170,93 & 4 & 167,85 \\
\hline Sağır (2000) & 3 & 159,17 & 1 & 164,97 & 4 & 162,07 \\
\hline
\end{tabular}

n: Birey say1s1

\section{C) Diş ve çene patolojileri}

Amasya ve çevresi Roma Dönemi bireylerinde, beslenme biçimleri, besin hazırlama teknikleri, beslenme alışkanlıkları, ağız sağlı̆̆ ve yaşam biçimleri hakkında bilgi edinebilmek amacıyla, bireylere ait toplam 196 diş (172 daimi, 24 süt), 223 daimi diş alveolü (64 üst, 159 alt) ve 22 çene parçası paleopatolojik açıdan incelenmiştir. Bu amaçla incelenen materyalde, diş aşınmas1, diş çürügü, hypoplasia, diştaş1, apse, alveol kayb1 ve ölüm öncesi diş kaybı gibi lezyonlar saptanmıştır.

\section{1) Diş aşınması}

Bebek ve çocuklarda incelenen 24 süt dişinin 16'sında (\% 66,67) diş aşınması saptanmıştır. Aşınan süt dişleri (alt çene + üst çene), Bouville ve diğerlerinin (1983) geliştirmiş olduğu aşınma ölçeğine göre derecelendirildiğinde, 1 (\% 56,2), 2 (\% 25) ve $2+\left(\begin{array}{l}\% \\ \%\end{array}\right.$ aşınmalar gözlenmiştir. Aşınmadan en fazla etkilenen diş grubu 1. büyük azı dişleridir. Diş aşınması dışında süt dişlerinde herhangi bir patolojik lezyona rastlanmamıştır.

Amasya bireylerine ait 172 daimi dişten 98'inde $(\%$ 56,98) diş aşınması tespit edilmiştir (Resim 1). Aşınan daimi dişler (alt çene + üst çene), Bouville ve diğerlerinin (1983) geliştirmiş olduğu aşınma ölçeğine göre derecelendirildiğinde, aşınmaların en fazla $3(\%$ 16,33) ve $5+(\%$ 15,31) düzeylerinde yoğunlaştığ1 görülmektedir (Tablo 5). Alt ve üst çene dişeri birlikte değerlendirildiğinde, aşınmadan en fazla etkilenen diş grubunun 2. büyük azı dişleri $(\% 26,53)$ olduğu görülür. 
Tablo 5: Amasya bireylerine ait daimi dişlerde görülen aşınma derecelerinin diş gruplarına göre dağılımı (alt çene + üst çene)

\begin{tabular}{|c|c|c|c|c|c|c|c|c|c|c|c|c|}
\hline $\begin{array}{c}\text { Üst+Alt } \\
\text { çene }\end{array}$ & $\mathbf{1}$ & $\mathbf{2}$ & $\mathbf{2 +}$ & $\mathbf{3}-$ & $\mathbf{3}$ & $\mathbf{3 +}$ & $\mathbf{4}$ & $\mathbf{4 +}$ & $\mathbf{5}$ & $\mathbf{5 +}$ & Toplam & $\mathbf{\%}$ \\
\hline $\mathbf{I 1}$ & 0 & 0 & 2 & 3 & 0 & 0 & 1 & 0 & 0 & 2 & 8 & 8,16 \\
\hline $\mathbf{I 2}$ & 3 & 0 & 0 & 2 & 1 & 2 & 0 & 1 & 0 & 2 & 11 & 11,22 \\
\hline $\mathbf{C}$ & 0 & 1 & 1 & 2 & 3 & 0 & 1 & 1 & 0 & 2 & 11 & 11,22 \\
\hline $\mathbf{P 1}$ & 1 & 0 & 1 & 0 & 4 & 1 & 0 & 0 & 0 & 0 & 7 & 7,14 \\
\hline $\mathbf{P 2}$ & 2 & 1 & 0 & 0 & 3 & 1 & 1 & 0 & 1 & 1 & 10 & 10,2 \\
\hline $\mathbf{M 1}$ & 0 & 1 & 1 & 0 & 3 & 2 & 2 & 3 & 1 & 1 & 14 & 14,29 \\
\hline $\mathbf{M 2}$ & 2 & 1 & 3 & 6 & 1 & 1 & 3 & 3 & 2 & 4 & 26 & 26,53 \\
\hline $\mathbf{M 3}$ & 3 & 0 & 0 & 0 & 1 & 1 & 0 & 1 & 2 & 3 & 11 & 11,22 \\
\hline Toplam & 11 & 4 & 8 & 13 & 16 & 8 & 8 & 9 & 6 & 15 & 98 & 100 \\
\hline
\end{tabular}

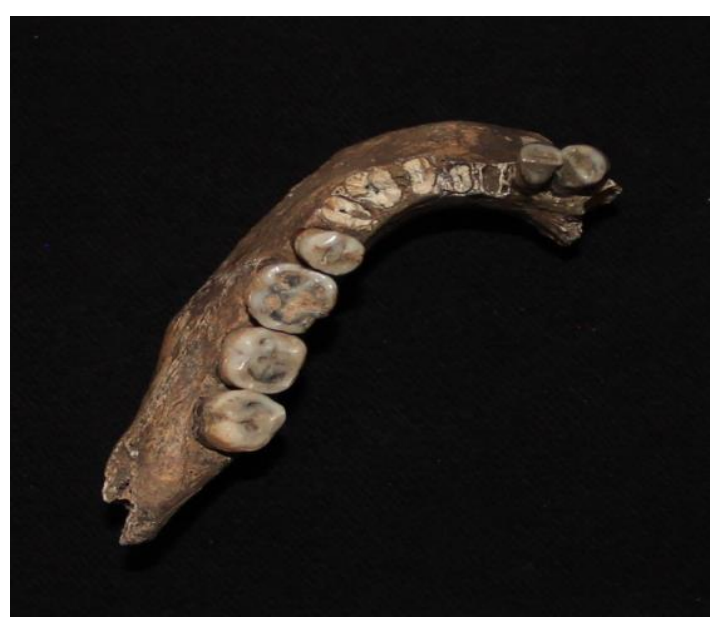

Resim 1: Diş aşınması

\section{2) Diş çürüğü}

Amasya bireylerine ait toplam 172 daimi diş çürük açısından değerlendirilmiş ve 8 dişte çürük saptanmıştır (\% 4,65) (Resim 2). Çürükler en fazla 1. daimi azı dişlerde gözlenmiştir $(\% 15,38)$. Alt ve üst çenede kesici dişlerde çürüğe rastlanmamıştır (Tablo 6). Bu lezyondan arka dişler ön dişlere göre daha fazla etkilenmiştir (Grafik 1). 
Tablo 6: Amasya bireylerine ait daimi dişlerde görülen diş çürüğünün diş gruplarına göre dağılımı

\begin{tabular}{|c|c|c|c|c|c|c|c|c|c|}
\hline \multirow{2}{*}{ Diş Gruplar1 } & \multicolumn{3}{|c|}{ Üst çene } & \multicolumn{3}{c|}{ Alt çene } & \multicolumn{3}{c|}{ Toplam } \\
\cline { 2 - 11 } & B & G & $\%$ & B & G & $\%$ & B & G & $\%$ \\
\hline M3 & 6 & 0 & 0 & 13 & 2 & 15,38 & 19 & 2 & 10,53 \\
\hline M2 & 12 & 0 & 0 & 19 & 1 & 5,26 & 31 & 1 & 3,23 \\
\hline M1 & 9 & 1 & 11,11 & 17 & 3 & 17,65 & 26 & 4 & 15,38 \\
\hline P2 & 8 & 0 & 0 & 16 & 0 & 0 & 24 & 0 & 0 \\
\hline P1 & 7 & 0 & 0 & 16 & 0 & 0 & 23 & 0 & 0 \\
\hline C & 6 & 1 & 16,67 & 14 & 0 & 0 & 20 & 1 & 0,5 \\
\hline İ2 & 7 & 0 & 0 & 10 & 0 & 0 & 17 & 0 & 0 \\
\hline İ1 & 6 & 0 & 0 & 6 & 0 & 0 & 12 & 0 & 0 \\
\hline Toplam & 61 & 2 & 3,28 & 111 & 6 & 5,41 & 172 & 8 & 4,65 \\
\hline
\end{tabular}

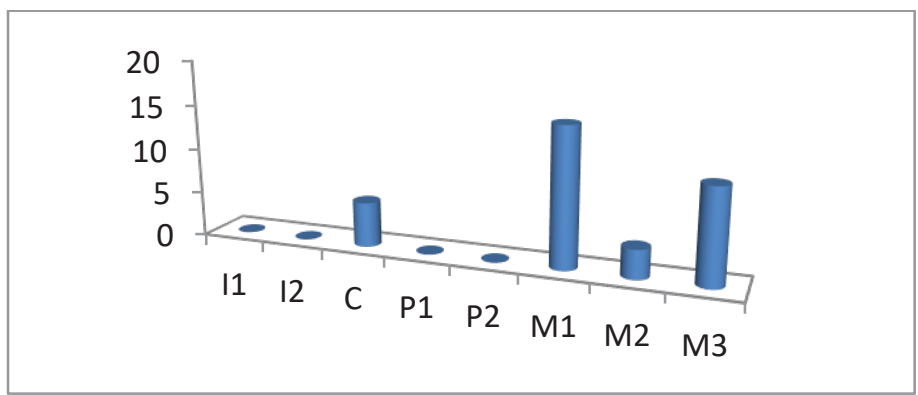

Grafik 1: Amasya bireylerine ait daimi dişlerde görülen diş çürüğünün diş gruplarına göre dağılımı 


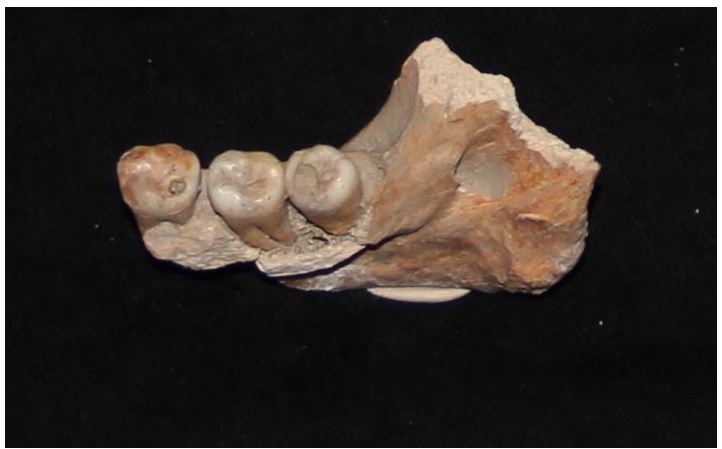

Resim 2: Oklüzyal yüzeyde görülen diş çürüğü

\section{3) Hypoplasia}

İncelenen toplam 172 daimi dişin 8'inde $(\%$ 4,65) hypoplasia oluşumuna rastlanmıştır. Hypoplasia oluşumu daimi dişlerde az derecede gelişim göstermiştir. Üst çenede hypoplasia görülme oranı \% 8,20 iken, alt çenede bu değer \% 2,70'dir. Alt ve üst çene dişleri bir arada değerlendirildiğinde bu lezyondan en fazla arka diş grupları etkilenmiştir (Tablo 7).

Tablo 7: Amasya bireylerine ait daimi dişlerde görülen hypoplasianın diş gruplarına göre dağılımı

\begin{tabular}{|c|c|c|c|c|c|c|c|c|c|}
\hline \multirow{2}{*}{ Diş Gruplar1 } & \multicolumn{3}{|c|}{ Üst çene } & \multicolumn{3}{c|}{ Alt çene } & \multicolumn{3}{c|}{ Toplam } \\
\cline { 2 - 11 } & B & G & \% & B & G & \% & B & G & $\%$ \\
\hline M3 & 6 & 1 & 16,67 & 13 & 0 & 0 & 19 & 1 & 5,26 \\
\hline M2 & 12 & 1 & 8,33 & 19 & 1 & 5,26 & 31 & 2 & 6,45 \\
\hline M1 & 9 & 1 & 11,11 & 17 & 1 & 5,88 & 26 & 2 & 7,69 \\
\hline P2 & 8 & 1 & 12,5 & 16 & 1 & 6,25 & 24 & 2 & 8,33 \\
\hline P1 & 7 & 1 & 14,29 & 16 & 0 & 0 & 23 & 1 & 4,35 \\
\hline C & 6 & 0 & 0 & 14 & 0 & 0 & 20 & 0 & 0 \\
\hline I2 & 7 & 0 & 0 & 10 & 0 & 0 & 17 & 0 & 0 \\
\hline I1 & 6 & 0 & 0 & 6 & 0 & 0 & 12 & 0 & 0 \\
\hline Toplam & 61 & 5 & 8,2 & 111 & 3 & 2,70 & 172 & 8 & 4,65 \\
\hline
\end{tabular}

\section{4) Diştaş1}

Amasya bireylerinde 172 daimi dişin 5’inde (\% 2,91) diştaş1 oluşumuna rastlanmıştır. Üst çene dişlerinde diştaşına rastlanmazken, lezyon alt çene dişlerini etkilemiştir. Bu oluşum en fazla 2. büyük azı dişinde $(\% 6,45)$ 
gözlenmiştir (Tablo 8). Diştaşı oluşumu genellikle az düzeyde gelişim göstermiştir.

Tablo 8: Amasya bireylerine ait daimi dişlerde görülen diştaşının diş gruplarına göre dağılımı

\begin{tabular}{|l|c|c|c|c|c|c|c|c|c|}
\hline \multirow{2}{*}{ Diş Gruplar1 } & \multicolumn{2}{|c|}{ Üst çene } & \multicolumn{3}{c|}{ Alt çene } & \multicolumn{3}{c|}{ Toplam } \\
\cline { 2 - 10 } & B & G & $\%$ & B & G & $\%$ & B & G & $\%$ \\
\hline M3 & 6 & 0 & 0 & 13 & 1 & 7,69 & 19 & 1 & 5,26 \\
\hline M2 & 12 & 0 & 0 & 19 & 2 & 10,5 & 31 & 2 & 6,45 \\
\hline M1 & 9 & 0 & 0 & 17 & 1 & 5,88 & 26 & 1 & 3,85 \\
\hline P2 & 8 & 0 & 0 & 16 & 1 & 6,25 & 24 & 1 & 4,17 \\
\hline P1 & 7 & 0 & 0 & 16 & 0 & 0 & 23 & 0 & 0 \\
\hline C & 6 & 0 & 0 & 14 & 0 & 0 & 20 & 0 & 0 \\
\hline I2 & 7 & 0 & 0 & 10 & 0 & 0 & 17 & 0 & 0 \\
\hline I1 & 6 & 0 & 0 & 6 & 0 & 0 & 12 & 0 & 0 \\
\hline Toplam & 61 & 0 & 0 & 111 & 5 & 4,5 & 172 & 5 & 2,91 \\
\hline
\end{tabular}

\section{5) Apse}

Amasya bireylerine ait toplam 223 daimi diş alveolünün 3'ünde $(\% \quad 1,35)$ apse oluşumu saptanmıştır (Resim 3). Apse üst çenede 3. büyük azı (6/1) ve 2. küçük azı dişlerinde (8/1) gözlenirken, alt çenede 1 . büyük azı dişi (18/1) bu lezyona maruz kalmıştır.

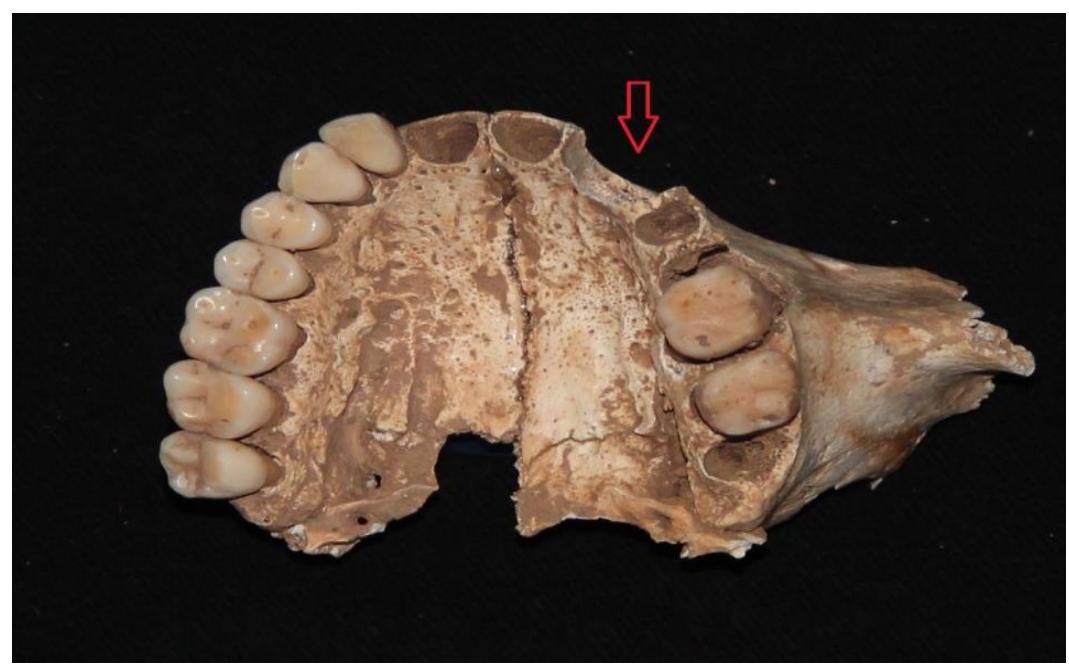

Resim 3: Üst çenede görülen apse oluşumu 


\section{6) Alveol kayb1}

Amasya bireylerine ait toplam 22 çenenin 8'inde $(\% \quad 36,3)$ alveol kayb1 gözlenmiştir (Resim 4). Genellikle az derecede gelişim gösteren alveol kayıpları alt çeneyi daha fazla etkilemiştir.

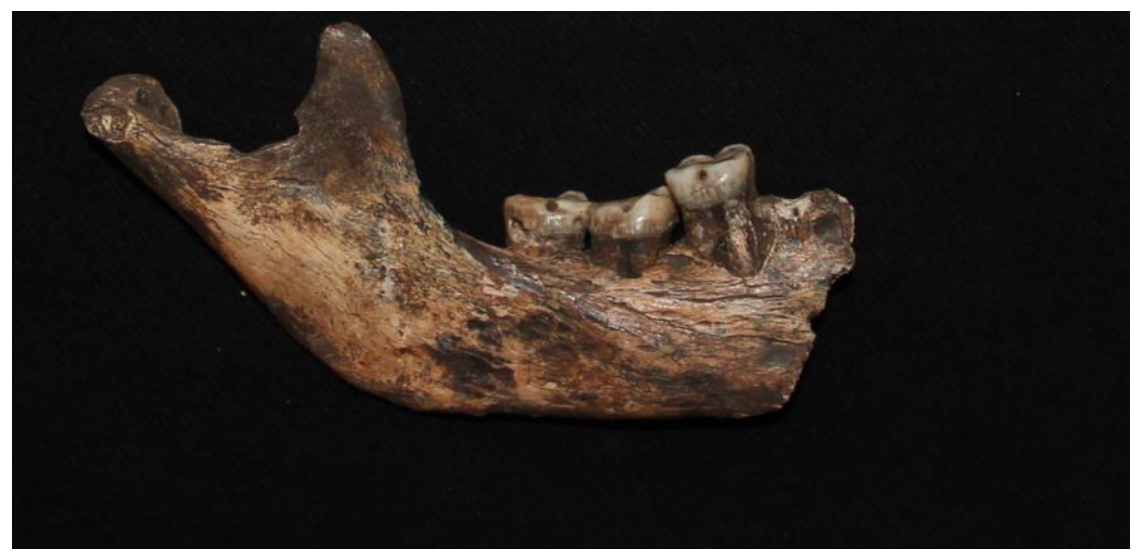

Resim 4: Alveol kayb1

\section{7) Ölüm öncesi (antemortem) diş kaybı}

Amasya bireylerine ait çenelerdeki toplam 223 daimi diş alveolü ölüm öncesi diş kaybının saptanması amacıyla incelenmiş ve 14 alveolde $(\% 6,28)$ bu oluşum gözlenmiştir (Resim 5). Ölüm öncesi diş kaybı üst çenede \% 9,38 oranında görülürken, alt çenede bu değer \% 5,03'tür. Bu lezyon en fazla 1 . büyük azı dişlerde gözlenmiştir (\% 26,92) (Tablo 9). 
Tablo 9: Amasya bireylerinde görülen ölüm öncesi diş kaybının alveol gruplarına göre dağılımı

\begin{tabular}{|l|c|c|c|c|c|c|c|c|c|}
\hline \multirow{2}{*}{ Alveol Gruplar1 } & \multicolumn{3}{|c|}{ Üst çene } & \multicolumn{3}{c|}{ Alt çene } & \multicolumn{3}{c|}{ Toplam } \\
\cline { 2 - 11 } & B & G & $\%$ & B & G & $\%$ & B & G & $\%$ \\
\hline M3 & 6 & 0 & 0 & 17 & 0 & 0 & 23 & 0 & 0 \\
\hline M2 & 9 & 0 & 0 & 18 & 2 & 11,11 & 27 & 2 & 7,41 \\
\hline M1 & 8 & 2 & 25 & 18 & 5 & 27,78 & 26 & 7 & 26,92 \\
\hline P2 & 8 & 1 & 12,5 & 22 & 1 & 4,55 & 30 & 2 & 6,67 \\
\hline P1 & 8 & 1 & 12,5 & 20 & 0 & 0 & 28 & 1 & 3,57 \\
\hline C & 9 & 0 & 0 & 24 & 0 & 0 & 33 & 0 & 0 \\
\hline I2 & 8 & 2 & 25 & 21 & 0 & 0 & 29 & 2 & 6,9 \\
\hline I1 & 8 & 0 & 0 & 19 & 0 & 0 & 27 & 0 & 0 \\
\hline Toplam & 64 & 6 & 9,38 & 159 & 8 & 5,03 & 223 & 14 & 6,28 \\
\hline
\end{tabular}

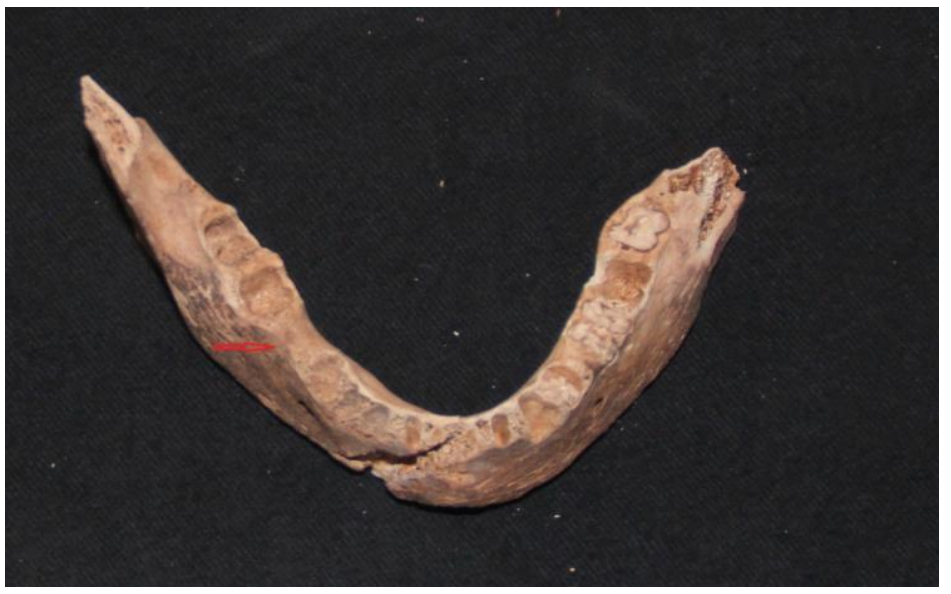

Resim 5: Ölüm öncesi (antemortem) diş kayb1

\section{IV) TARTIŞMA VE SONUÇ}

Amasya ili ve çevresinde 1992-2002 yılları arasında Amasya Müze Müdürlüğü başkanlığında Roma Dönemi'ne tarihlendirilen arkeolojik alanlarda yapılan kurtarma kazıları sonucunda, toplam 56 bireye ait iskelet kalıntıları ele geçirilmiştir. Bu bireylerin 2'si bebek ( \% 3,57), 11'i çocuk (\% 
19,64), 15’i kadın (\% 26,79), 13'ü erkek (\% 23,21) ve 15’i de cinsiyeti saptanamayan bireyler (\% 26,79) olarak tanımlanmıştır. İncelenen bireylerin \% 76,79'u erişkin bireylerden (n: 43), \% 23,21'i bebek ve çocuklardan (n: 13) oluşmaktadır. Bebek ve çocuklarda ikişerli yaş aralıklarına göre yaş dağılımı incelendiğinde, en fazla ölümlerin 4-5,9 (\% 30,77) yaş aralığı arasında gerçekleştiği görülmektedir. Kötü ve yetersiz beslenme, sağlık koşullarının iyi olmamas1, salgin hastalıklar gibi faktörlerin sonuçta etkili olabileceği düşünülmektedir. 10-15,9 yaş aralığında bireylere rastlanmamıştır. Toplumun geneline bakıldığında, erişkin bireylerin \% 3,57'si genç erişkinlerden (18-25 yaş), \% 71,42’i orta erişkinlerden (25-45 yaş) ve \% 25’i ileri erişkinlerden $(45+$ yaş) oluşmaktadır. Özellikle ölümler orta yaş grubunda yoğunlaşmaktadır. Kadın ve erkeklerde ölümlerin hangi yaş aralıklarında yoğunlaştığını saptamak amacıyla beşerli yaş aralıklarına göre yaş gruplamaları yapılmış, buna göre en fazla ölümlerin kadınlarda 40-45, erkeklerde ise 25-30 ve 30-35 yaş aralıklarında yoğunlaştığ1 görülmüştür. Erkeklerde bu yaşlarda ölümlerin yoğun olmasının savaşlardan kaynaklanabileceği düşünülmektedir. Kadınlardaki yoğun ölüm aralığı ileri erişkin yaş grubunda gerçekleşmiştir.

İncelenen bireylerde ortalama boy uzunlukları, Pearson'a (1899) göre 161,58 (n: 4), Trotter-Gleser'e (1952) göre 167,85 (n: 4) ve Sağır'a (2000) göre 162,07 (n: 4) olarak saptanmıştır. Görüldüğü üzere, erkekler kadınlardan daha uzun boyludur.

Amasya ili ve çevresinde Roma Dönemi'nde yaşamış bireylere ait daimi dişlerin ve çenelerin paleopatolojik açıdan incelenmesi sonucunda elde edilen veriler bir arada değerlendirildiğinde, diş aşınması \% 56,98 diş çürüğü \% 4,65, hypoplasia $\% 4,65$, diştaş1 \% 2,91, apse $\% 1,35$, alveol kayb1 \% 36,3 ve ölüm öncesi (antemortem) diş kaybı \% 6,28 oranında görülmektedir. Elde edilen sonuçlar yakın dönemde yaşamış ve çağdaşı diğer eski Anadolu toplumlardan elde edilen verilerle karşılaştırıldığında şöyle bir tablo ortaya çıkmaktadır (Tablo 10). 
Tablo 10: Amasya bireylerine ait daimi dişlerde ve çenelerde görülen patolojik oluşumların eski Anadolu toplumlarıyla karşılaştırılması

\begin{tabular}{|c|c|c|c|c|c|c|c|c|}
\hline Toplum & Dönem & Araştırıcı & Çürük & $\begin{array}{c}\text { Hypoplasi } \\
\text { a }\end{array}$ & $\begin{array}{c}\text { Diştaş } \\
1\end{array}$ & Apse & $\begin{array}{c}\text { Alveo } \\
1 \\
\text { Kayb } \\
1\end{array}$ & $\begin{array}{c}\text { AMT } \\
\text { L }\end{array}$ \\
\hline $\begin{array}{l}\text { Klazomenai } \\
\text { - Yildiztepe }\end{array}$ & $\begin{array}{l}\text { Helenisti } \\
\mathrm{k}\end{array}$ & $\begin{array}{l}\text { Güleç } \\
\text { (1985) }\end{array}$ & 5,2 & - & - & - & - & 3,7 \\
\hline $\begin{array}{l}\text { Klazomenai } \\
\text { - Akpınar }\end{array}$ & $\begin{array}{l}\text { Helenisti } \\
\mathrm{k}\end{array}$ & $\begin{array}{l}\text { Güleç ve } \\
\text { diğ., (1998) }\end{array}$ & 5,4 & 35 & 12,5 & & & 3,4 \\
\hline Antandros & $\begin{array}{l}\text { Helenisti } \\
\mathrm{k}\end{array}$ & Erdal (2001) & 9,8 & 60,3 & - & 5,4 & - & 17,5 \\
\hline $\begin{array}{l}\text { Gümüşlük- } \\
\text { Milas }\end{array}$ & $\begin{array}{l}\text { Helenisti } \\
\mathrm{k}\end{array}$ & $\begin{array}{l}\text { Sağır ve } \\
\text { diğ., (2010) }\end{array}$ & 10,42 & 41,25 & 65 & $\begin{array}{c}13,5 \\
7\end{array}$ & - & 20 \\
\hline Panaztepe & Roma & $\begin{array}{l}\text { Güleç ve } \\
\text { Duyar } \\
(1998)\end{array}$ & 11,11 & 22,73 & 14,75 & - & - & 11,11 \\
\hline Laodikeia & Roma & $\begin{array}{l}\text { Şimşek } \\
\text { (2011) }\end{array}$ & 2,62 & 11,36 & 31,23 & 3,8 & 50,61 & 7,78 \\
\hline Amasya & Roma & & 4,65 & 4,65 & 2,91 & 1,35 & 36,3 & 6,28 \\
\hline Sardis & $\begin{array}{l}\text { G.Roma } \\
\text { E.Bizans }\end{array}$ & $\begin{array}{l}\text { Eroğlu } \\
\text { (1998) }\end{array}$ & 8,7 & 64,54 & 50,52 & 7,26 & 82,31 & 16,04 \\
\hline Kirazlıdere & $\begin{array}{l}\text { E. } \\
\text { Bizans }\end{array}$ & $\begin{array}{l}\text { SuataAlpasl } \\
\text { an ve Uz } \\
(2017)\end{array}$ & 7,8 & 38,29 & 67,37 & 9,21 & 56,81 & 35,23 \\
\hline Çiçekdağ1 & $\begin{array}{l}\text { E. } \\
\text { Bizans }\end{array}$ & $\begin{array}{l}\text { Alkan ve } \\
\text { diğ. (2014) }\end{array}$ & 5,66 & 22,64 & 1,88 & 0 & 33 & 9,09 \\
\hline $\begin{array}{l}\text { Smyrna } \\
\text { Agoras1 }\end{array}$ & Bizans & $\begin{array}{l}\text { Gözlük ve } \\
\text { diğ., (2006) }\end{array}$ & 4,68 & 11,7 & 16,96 & 1,63 & 32,33 & 7,61 \\
\hline $\begin{array}{l}\text { Adramyttei } \\
\text { on } \\
\text { (Örentepe) }\end{array}$ & Bizans & $\begin{array}{l}\text { Atamtürk ve } \\
\text { Duyar } \\
(2008)\end{array}$ & 10,1 & 60,23 & 29,61 & 1,36 & 80 & 9,43 \\
\hline Kyzikos & Bizans & $\begin{array}{l}\text { Gözlük ve } \\
\text { diğ., (2009) }\end{array}$ & 7,76 & 56,73 & 5,31 & - & 100 & 3,79 \\
\hline
\end{tabular}




\begin{tabular}{|l|l|l|c|c|c|c|c|c|}
$\begin{array}{l}\text { Alanya } \\
\text { Kalesi }\end{array}$ & Bizans & $\begin{array}{l}\text { Üstündağ ve } \\
\text { Demirel } \\
(2009)\end{array}$ & 12,6 & 39,7 & 29,6 & 2,3 & 35,3 & 2,8 \\
\hline $\begin{array}{l}\text { Tios / } \\
\text { Filyos }\end{array}$ & Bizans & $\begin{array}{l}\text { Çırak ve } \\
\text { Çırak (2015) }\end{array}$ & 3,86 & 1,63 & 6,1 & 1,6 & 8,88 & 12,81 \\
\hline İznik & $\begin{array}{l}\text { G. } \\
\text { Bizans }\end{array}$ & Erdal (1996) & 10,88 & 36,8 & 59,28 & 3,93 & 70,83 & 7 \\
\hline $\begin{array}{l}\text { Büyük } \\
\text { Saray Eski } \\
\text { Cezaevi }\end{array}$ & G.Bizans & Erdal (2003) & 9,6 & 75,4 & 57,2 & 5,1 & 33,1 & 12 \\
\hline $\begin{array}{l}\text { Zeytinli } \\
\text { Ada }\end{array}$ & $\begin{array}{l}\text { Hel- } \\
\text { Roma- } \\
\text { Bizans- } \\
\text { Osmanlı }\end{array}$ & $\begin{array}{l}\text { Blp̧ak ve } \\
\text { (2015) }\end{array}$ & 4,9 & 42,64 & 71,07 & 6,61 & 89,46 & 38,27 \\
\hline
\end{tabular}

Buna göre, Amasya ve çevresinde Roma Dönemi'nde yaşamış bireylerde görülen diş ve çene patoloji sonuçları, özellikle hypoplasia ve diştaşı açısından, diğer eski Anadolu toplumlarının çoğundan düşük değerler vermiştir.

Amasya bebek ve çocuklarında süt dişlerinde aşınma dişında $(\% 66,6)$ herhangi bir lezyona rastlanmamıştır.

Amasya bireylerinin daimi dişlerinde gözlenen diş aşınma dereceleri özellikle $3(\% 16,33)$ ve $5+(\% 15,31)$ derecelerde yoğunlassmaktadır. Bu sonuca göre, bu insanların beslenme sistemlerinde sert ve lifli besinlerin varlığından söz edebiliriz. Dişlerde gözlenen çürük yüzdesi $(\% 4,65)$ çok yüksek değildir, fakat karbonhidratça zengin, rafine gıdaları tükettiklerini göstermektedir. Yani tarımsal beslenmeyi desteklemektedir. Hypoplasia oluşumu oldukça düşük bir değerle karşımıza çıkmaktadır (\% 4,65), aynı zamanda gelişimide az derecededir. $\mathrm{Bu}$ sonuç, incelenen bireylerin bebeklik ve çocukluk aşamalarında yoğun streslere maruz kalmadıklarını düşündürmektedir. Diştaşı (\% 2,91) ve alveol kaybı (\% 36,3) yoğunlukla az derecede gelişim göstermiştir. Bu lezyonlar ağız bakımı ve hijyeniyle ilişkilendirilir. Düşük bir oranla karşımıza çıkan apse oluşumundan $(\% 1,35)$ diş çürüğünün sorumlu olduğu düşünülmektedir. Ölüm öncesi (antemortem) diş kayb1 $(\% 6,28)$ düşük değerdedir. Bireyin yaşarken dişlerini kaybetmesine neden olabilecek ileri derecelerde patolojik lezyonlar çok fazla derecede gözlenmemiştir.

Kazı alanlarında bireylerin yaşam biçimlerini ya da sosyal statülerini gösteren herhangi bir arkeolojik kalıntıya rastlanmamıştır. Fakat dişlerde ve çenelerde saptanan lezyonlar, bireylerin beslenme biçimleri, besin hazırlama 
teknikleri, yaşam biçimleri gibi birçok konuda bilge verebilmektedir. İki tarafı kayalıklarla çevrili, dar bir vadi konumunda olan Amasya'da genel ekonomik yapıyı tarım, hayvancılık ve ticaret oluşturmaktadır. Özellikle verimli ovaları, iklimi, tarıma elverişli alanların bol olması nedeniyle ekonomide tarım ilk sırayı almaktadır. Buğday, arpa, mısır, kiraz, elma yetiştirilen ürünler arasındadır. Amasya hayvancılık yönünden de önemli bir potansiyele sahiptir, (http://www.amasya.gov.tr). İklim ve coğrafik koşullar tarım ve hayvancılığı desteklemektedir. Dolayısıyla Amasya Roma Dönemi bireylerinin günümüze benzer bir ortamda yaşadığı, benzer bir beslenme biçimine sahip olduğu, beslenme sistemlerinde proteince zengin besinlere de ağırlık verdikleri düşünülmektedir.

İncelenen iskelet kalıntılarının tek bir mezarlık alanından değil de, Amasya ili ve çevresinde yer alan ve Roma Dönemi'ne tarihlendirilen birkaç mezarlık alanından çıkarılmasının sonuçta etkili olmuş olabileceği düşünülmektedir. Bu çalışma, Roma Dönemi'nde yaşamış Amasya bireylerine ilişkin genel bilgi vermesi açısından önem taşımaktadır.

\section{TEŞEKKÜR}

Amasya ili ve çevresi kurtarma kazılarından ele geçen ve Roma Dönemi'ne tarihlendirilen bu iskeletleri çalışmamız için olanak sağlayan ve yardımlarını esirgemeyen, çalıştığımız dönemde Amasya Müze Müdürü olarak görev yapan sayın Celal Özdemir'e teşekkürü bir borç biliriz. 


\section{KAYNAKÇA}

Akbacak, H. (2018). Amasya Roma Dönemi İskeletlerinin Antropolojik Analizi. (Basılmamış Yüksek Lisans Tezi). Cumhuriyet Üniversitesi, Sivas.

Alkan, Y., Erkman, A.C., Kaplan, İ. (2014). "Çiçekdağ1 İskeletlerinin Paleoantropolojik Analizi”. 29. Arkeometri Sonuçları Toplantısı, 77-82.

Atamtürk, D. ve Duyar, İ. (2008). “Adramytteion (Örentepe) İskeletlerinde Ağı ve Diş Sağlığı”. Hacettepe Üniversitesi Edebiyat Fakültesi Dergisi, 25 (1): 1-15.

Başoğlu, O. (2012). "Nevşehir/Camihöyük Helenistik-Roma Dönemi İnsanlarının Sağlık Sorunları”. Olba, 20: 1-27.

Başoğlu, O., Şener, T., Gökkoyun, S. (2012). “Olba İskeletleri”, Adli Bilimler Dergisi, Cilt 11, 2: 15-25.

Bıçak, S. ve Suata Alpaslan F. (2015). "Zeytinli Ada İskelet Topluluğunun Diş ve Çene Patolojisi Açısından İncelenmesi”. C.Ü. Fen Fakültesi, Fen Bilimleri Dergisi (CFD), 36 (5): 32-46.

Bouville, C., Constandse-Westermann, S.T. ve Newell R.R. (1983). Les Restes Humains Mesolithiques de I'Abri Corbille, Istres (Bouches du Rhone), Bullet Mem., de la Sos. D’Anthrop. De Paris, 5 / XIII, 89-110.

Brothwell, D.R. (1981). Digging Up Bones. Oxford: Oxford University Press.

Buikstra, J.E., Ubelaker, D.H. (1994). Standards: For Data Collection From Human Skeletal Remains. Arkansas Archeological Survey Research Series No: 44.

Çatal, A.Ç. (2009). 19. Yüzyılın İkinci Yarısında Amasya Şehri'nin Demografik Yapısı ve İskan Siyaseti. (BasılmamışYüksek Lisans Tezi). Niğde Üniversitesi Sosyal Bilimler Enstitüsü, Niğde.

Çırak, A. ve Çırak M.T. (2015). "Tios/Filyos İskelet Kalıntılarının Paleoantropolojik Analizi”. 30. Arkeometri Sonuçları Toplantısı, 167174.

Er, F. (2009). XV ve XVI Yüzyılda Amasya. (Basılmamış Yüksek Lisans Tezi). Gazi Üniversitesi Sosyal Bilimler Enstitüsü, Ankara.

Erdal, Y.S. (2003). "Büyük Saray - Eski Cezaevi Çevresi Kazılarında Gün Issığına Çıkarılan İnsan Kalıntılarının Antropolojik Analizi”. 18. Arkeometri Sonuçları Toplantısı, 15- 30.

Erdal, Y.S. (1996). İznik Geç Bizans Dönemi İnsanlarının Çene ve Dişlerinin Antropolojik Açıdan İncelenmesi. (Basılmamış Doktora Tezi), Hacettepe Üniversitesi Sosyal Bilimler Enstitüsü, Ankara. 
Erdal, Y.S. (2001). "Antandros İnsanlarında Ağız ve Diş Sağlığı". Türk Arkeoloji ve Etnografya Dergisi, 1: 45-55.

Eroğlu, S. (1998). Sardis Roma-Bizans Toplumlarında Diş Hastalıkları ve Ağız Sağlığı. (BasılmamışYüksek Lisans Tezi). Ankara Üniversitesi Sosyal Bilimler Enstitüsü, Ankara.

Gözlük, P., Durgunlu, Ö., Özdemir, S., Taşlıalan, M., Sevim, A. (2006). "Symrna Agoras1 İskeletlerinin Paleoantropolojik Analizi". 21. Arkeometri Sonuçları Toplantısı, 125-140.

Gözlük, P., Başoğlu, O., Pehlevan, C., Eser, E., Kocaoğlu, B., Topdemir, H., Torun, N. (2016). "Tarsus (Makam Cami) İnsanlarında Ağız ve Diş Sağlı̆̆ı". Hitit Üniversitesi Sosyal Bilimler Enstitüsü Dergisi, 9 (1): 99118.

Güleç, E. (1985). "Klazomenai İskeletlerinin Antropolojik ve Demografik İncelenmesi”. 1. Arkeometri Sonuçları Toplantısı, 131-138.

Güleç, E., İ. Duyar. (1998). "Panaztepe M.Ö. 2. bin ve Roma Dönemi İskeletlerinin Antropolojik Analizi”. Antropoloji Dergisi, 13: 179-206.

Güleç, E., Sevim, A., Özer, İ., Sağır, M. (1998), “Klazomenai'de Yaşamış İnsanların Sağlık Sorunları”, 13. Arkeometri Sonuçları Toplantısı, 133159.

Hillson S. (1990). Teeth. New York: Cambridge University Press.

Kaur, H., Jit, I. (1990). "Age Estimation from Cortical Index of the Human Clavicle in Northwest Indians". American Journal of Physical Antropology, 83: 297-305.

Kertil, F. (2014). Büyük Selçuklu Döneminden Osmanlı Yönetimine Kadar Amasya Tarihi. (Basılmamış Yüksek Lisans Tezi). Ondokuz Mayıs Üniversitesi Sosyal Bilimler Enstitüsü, Samsun.

Kırmızığlu Gözlük, P., Yaşar, Z. F., Yiğit, A., Sevim Erol, A. (2009). "Kyzikos İskeletlerinin Dental Analizi”. 24. Arkeometri Sonuçları Toplantısı, 139162.

Olivier, G. (1969). Practical Anthropology. Springfield, Illionis: Charles C. Thomas Publisher.

Ortner, D.J., Putschar, W.G.J. (1985). Identification of Pathological Conditions in Human Skeletal Remains. Washingto, London: Smithsonian Institution.

Özbey, A.S. (2010). Amasya İli Höyükleri. (Basılmamış Yüksek Lisans Tezi). Atatürk Üniversitesi Sosyal Bilimler Enstitüsü, Erzurum. 
Pearson, K. (1899). Mathematical Contrubition on the Theory of Evolution: On the Reconstruction of the Stature of Prehistoric Races. Philosophical Transactions of the Royal Society 192, 169-244.

Sağır, M. (2000). Uzun Kemik Radyografilerinden Boy Formülü Hesaplaması. (Basılmamış Doktora Tezi). Ankara Üniversitesi Sosyal Bilimler Enstitüsü Fizik ve Paleoantropoloji (Fizik Antropoloji) Anabilim Dalı, Ankara.

Sağır, M., Satar, Z., Özer, İ., Güleç, E. (2010). "Gümüşlük- Milas İskeletlerinin Ağız ve Diş Sağlı̆̆ı”. 25. Arkeometri Sonuçları Toplantısı, 69-78.

Suata Alpaslan, F., Uz, B. (2017). "Kirazlıdere İskelet Topluluğunun Çene ve Diş Patolojisi Açısından İncelenmesi”. C.Ü. Sosyal Bilimler Dergisi, 41 (2): 1-19.

Szilvassy, J., Kritscher, H. (1990). Estimation of Chronological Age in Man Based on the Spongy Structure of Long Bones. Anthrop. Anz., 48: 159 $-164$.

Şahin, İ., Emecen, F. (1991). “Amasya”. TDİA, CIII. 1-4, İstanbul.

Şimşek, N. (2011). Laodikeia Populasyonun Diş ve Çenelerinin Paleopatolojik Açıdan Íncelenmesi. (Basılmamış Doktora Tezi). Sosyal Bilimler Enstitüsü, Ankara.

Trotter M., Gleser G.S. (1952). "Estimation of Stature from Long Bones of American Whites and Negroes". American Journal of Physical Anthropology, 10: 463-7514.

Ubelaker, D.H. (1978). Human Skeletal Remains. Chicago: Smithsonian Institution, Aldine Publisering Company.

Üstündağ, H., Demirel, F.A. (2009). "Alanya Kalesi İskelet Topluluğunda Ağız ve Diş Sağlığı”. Edebiyat Fakültesi Dergisi, 26 (1): 219-234.

White, D.T. (2000). Human Osteology, Second Edition, U.S.A.: Academic Press.

Workshop of European Anthropologists (WEA). (1980). "Recommendations for Age and Sex Diagnoses of Skeleton". Journal of Human Evolutions, 9 (7), 517-549.

Erişim Tarihi: 07.08.2018

http://www.amasyakulturturizm.gov.tr/TR,59475/tarihce.html).

Erişim Tarihi: 15.08.2018 (http://www.amasya.gov.tr). 
